\title{
ON THE SPECTRUM OF TOEPLITZ OPERATORS WITH QUASI-HOMOGENEOUS SYMBOLS
}

\author{
BARUSSEAU BENOIT
}

Abstract. In this paper, we fully describe the spectrum of a Toeplitz operator with quasi-homogeneous symbol and give formulas for the calculation of the spectral radius in the case where it is maximal. Finally, Theorem 4 gives equivalent conditions on the quasi-homogeneous function $F$ to have $\left\|T_{F}\right\|=\|F\|_{\infty}$. As a corollary we obtain some necessary and sufficient conditions for such Toeplitz operators to verify the equality $\sigma\left(T_{F}\right)=F(\mathbb{D})$.

Mathematics subject classification (2010): 47B35.

Keywords and phrases: Toeplitz operator, Bergman space, Spectrum, quasi-homogeneous symbol, norm, Berezin transform.

\section{REFERENCES}

[1] Sheldon Axler And Dechao Zheng, Compact operators via the Berezin transform, Indiana Univ. Math. J., 47, 2 (1998), 387-400.

[2] ŽEluko ČučKović, Berezin versus Mellin, J. Math. Anal. Appl., 287, 1 (2003), 234-243.

[3] R. G. DougLas, Banach algebra techniques in the theory of Toeplitz operators, American Mathematical Society, Providence, R.I., 1973. Expository Lectures from the CBMS Regional Conference held at the University of Georgia, Athens, Ga., June 12-16, 1972, Conference Board of the Mathematical Sciences Regional Conference Series in Mathematics, No. 15.

[4] S. GRUDSKY AND N. VASILEVSKI, Bergman-Toeplitz operators: radial component influence, Integral Equations Operator Theory, 40, 1 (2001), 16-33.

[5] Boris Korenblum And Ke He ZHU, An application of Tauberian theorems to Toeplitz operators, J. Operator Theory, 33, 2 (1995), 353-361.

[6] Issam Louhichi, Elizabeth Strouse, And Lova Zakariasy, Products of Toeplitz operators on the Bergman space, Integral Equations Operator Theory, 54, 4 (2006), 525-539.

[7] G. McDonald And C. SundberG, Toeplitz operators on the disc, Indiana Univ. Math. J., 28, 4 (1979), 595-611.

[8] Nikolai K. Nikolski, Operators, functions, and systems: an easy reading. Vol. 1, volume 92 of Mathematical Surveys and Monographs, American Mathematical Society, Providence, RI, 2002. Hardy, Hankel, and Toeplitz, Translated from the French by Andreas Hartmann.

[9] Allen L. Shields, Weighted shift operators and analytic function theory, in Topics in operator theory, pages 49-128. Math. Surveys, No. 13. Amer. Math. Soc., Providence, R.I., 1974.

[10] C. SundBerg AND D. ZHENG, The spectrum and essential spectrum of toeplitz opeators with harmonic symbols, preprint.

[11] Harold Widom, On the spectrum of a Toeplitz operator, Pacific J. Math., 14 (1964), 365-375.

[12] Lova ZAKariasy, The rank of Hankel operators on harmonic Bergman spaces, Proc. Amer. Math. Soc., 131, 4 (2003), 1177-1180 (electronic).

[13] De Chao Zheng, Toeplitz operators and Hankel operators, Integral Equations Operator Theory, 12, 2 (1989), 280-299.

[14] Ke He ZHU, Operator theory in function spaces, volume 139 of Monographs and Textbooks in Pure and Applied Mathematics, Marcel Dekker Inc., New York, 1990. 